\title{
PERFORMANCE CHARACTERISTICS OF LOW CARBON WASTE MATERIAL TO STABILISE SOIL WITH EXTREMELY HIGH PLASTICITY
}

\author{
Ali Al-Baidhani*, Abbas Jawad Al-Taie \\ Al-Nahrain University, College of Engineering, Civil Engineering Department, Al-Jadriya, 10070, Baghdad, Iraq \\ * corresponding author: al.baidhani7471@gmail.com
}

\begin{abstract}
The application of low-carbon and natural materials to mitigate the undesired properties of difficult soils is considered as a sustainable solution to the issues regarding these soils. Selecting some natural materials, of low carbon type, from the rubble of demolished buildings or debris from the construction of new buildings and recycling them in a poor or weak soil stabilisation process is a very little explored field of research in Iraq. This paper investigated the geotechnical characteristics of extremely high plasticity soil (EHPS) improved with a low-carbon building stone debris (BSD). Five dosages from coarse and fine soil-size ((BSDC) and (BSDF)) of BSD have been prepared to use in the EHPS-BSD mixtures. The laboratory tests included Atterberg limits, linear shrinkage, unconfined compression, consolidation, and swelling. The effect of the BSD on the time to zero-water content and the maximum swell was included. The efficiency of the BSD was proved by the amelioration of the compressibility and strength, and by reducing the shrinkage, swell pressure, and the potential of swelling. The shrinkage, compressibility, and swelling properties of the EHPS were reduced depending on the gradation and content of BSD. The gradation of BSD had a major role in strength development and controlling the time required to reach the final shrinkage and maximum swell stage.
\end{abstract}

KEYWORDS: Low carbon materials, extremely high plasticity soil, swelling shrinkage.

\section{INTRODUCTION}

High plasticity soils (HPS) have unsought properties upon wetting and drying like shrinkage and expansion. These soils exhibit a considerable shrinkage/swelling when their water or moisture content is subjected to a seasonal fluctuation [1, 2]. The unsought properties of HPS have negative effects on the strength and compressibility of these soils, as such, HPS are considered as unfavourable and unsuitable soils to be used as foundation materials. The construction of different engineering infrastructures on HPS represents a big challenge for engineers. Where HPS occur, they are difficult as layers for roads or as foundations for light structures. Due to the unfavourable properties of HPS, their difficult nature, and their widespread presence across the world, these soils have gained worldwide attention. Therefore, high plasticity soils need an enhancement in their index and mechanical properties [2] 4].

There are numerous ways one can utilise and adopt in the enhancement processes of properties of difficult soils, such as electrical, mechanical, chemical, physical, and biological treatment methods. For more sustainable technologies, recycling of waste material for the soil stabilization is also applied. However, mitigating the particle volume changes in the HPS by chemical alternation is among the most effective stabilisation techniques that gained the acceptance of geotechnical engineers $[5-22$. The efficiency of the stabilising material (economic and design) is an important factor that affects the chemical stabilizer selection. Also, the impacts of the selected stabilizer on the environment should be kept in mind. Improvement technologies of difficult soils have to be used within a manner that take into account the environmental aspects so as not to cause adverse effects to the environment (soil, air, and water). Hence, an improvement and stabilisation of soils using low-carbon natural materials are highly encouraged [2, 22, 23. Using such materials is considered a sustainable solution to the problems of difficult soils [23].

There is a number of materials defined as "low carbon materials", LCM. Among these materials are lime, rice-husk (reactive ash), fly ash, silica fume, granulated slag, blended cement, natural stones, stone dust, and several liquid materials like "sodium silicatebased" 23 26]. Materials like "ground-granulated blast-furnace slag", which have low carbon emissions, have been used in improving expansive soil. Such an application causes a positive reduction in the emissions of carbon dioxide. The solid block units produced from the compaction of the mixture of soil, lime, and water are considered as the LCM and eco-friendly construction material [2, 27]. The use of high volumes of coal fly ash, silica fume, rice-husk (reactive ash), or granulated slag in the cement manufacturing process produced a low carbon cement called blended cement. Also, the compacted mixture of stone dust, fly ash, and lime is used to produce a block with a high density, such a block has been considered as LCM. Natural materials like stones, biomass, and soil are considered 
ideal building materials [18, 19. Such materials were considered as ideal due to their low emission of carbon, recycling potential, reusability, and a low carbon footprint. The "cement stabilized rammed earth" is another material that was proven to be low-carbon material [28]. Also, the autoclaved dredged mud-brick is another LCM. This material is produced by mixing $10 \%$ of fly ash, $12 \%$ of steel slag, and $15 \%$ of calcium carbide with dredged soil [29]. Furthermore, the "ground granulated blast furnace slag - GBS" has been considered as a sustainable LCM. The rammed earth (including different additives like lime or gravel and sand), for wall construction purposes, has been used as LCM. In addition, some of the natural stones were, also, referred to as being LCM [25, 30]. In the last years, 31, a low carbon liquid additive named "sodium silicate-based" has been used to improve the compressibility and strength properties of soils. The application of "sodium silicate-based" was considered as a sustainable solution to the problems of expansive soil. This is due to the composition of this material, it is mainly composed of elements like $\mathrm{Si}$, Na, Fae, and $\mathrm{Al}$, therefore, it is classified as LCM. Based on the chemical composition of the material, tile factory waste was also classified as an LCM and considered as a successful stabiliser to improve the properties of clay soil. It was found that the waste of tiles is mainly composed of sodium, silicon, oxygen, and magnesium [31]. Recent studies emphasised the geoenvironmental issue regarding the stabilisation of expansive soils. These studies show the necessity of sustainability of soil stabilisation processes. Avoiding parameters (like dosage and type of additive) that cause adverse effects on the environment (like emission of carbon) should be considered. It is undesirable to use additives with a high carbon or heavy metal content in the soil stabilisation processes 32 .

Selecting some natural materials of LCM type from the rubble of demolished buildings or debris from the construction of new buildings and recycling them in a poor or weak soil stabilisation process is a very little explored field of research in Iraq. In this work, low-carbon natural building stone debris (BSD) was selected as a solid additive to ameliorate the geotechnical characteristics of extremely high plasticity soil (EHPS). Extensive laboratory testing was carried out. BSD was prepared in two different sizes to use in EHPS-BSD mixtures, these are coarse soil-size and fine soil-size, denoted as BSDC and BSDF, respectively. Five dosages of each BSD size used, ranging from $10 \%$ to $50 \%$, with an increment of $10 \%$, were prepared. Experiments included Atterberg limits, linear shrinkage, unconfined compression, consolidation, and swelling tests. Also, the effect of curing on the development of soil strength has been included.

\begin{tabular}{lc}
\hline Soil Properties & Values \\
\hline Color & Yellow \\
Specific Gravity, Gs & 2.58 \\
Sand fraction $(0.06-2 \mathrm{~mm}, \%)$ & 0 \\
Silt fraction $(0.002-0.06 \mathrm{~mm}, \%)$ & 18 \\
Clay fraction (less than $0.002 \mathrm{~mm})$ & 82 \\
Liquid limit, $w_{L}(\%)$ & 139 \\
Plastic limit, $w_{p}(\%)$ & 43 \\
Plasticity Index, Ip (\%) & 96 \\
Soil Activity, A & 1.17 \\
BSCS & $\mathrm{CE}$ \\
Optimum water content (\%) & 35 \\
Maximum dry density, g/cm ${ }^{3}$ & 1.23 \\
Silicon, Si (\%) & 20.71 \\
Aluminium, Al (\%) & 6.68 \\
Calcium, Ca $(\%)$ & 3.38 \\
Magnesium, Mg (\%) & 2.14 \\
Iron, Fe (\%) & 0.62 \\
Sodium, Na (\%) & 0.75 \\
Nitrogen, N (\%) & 1.57 \\
Oxygen, O (\%) & 60.88 \\
Carbon, C (\%) & 0.00 \\
\hline
\end{tabular}

TABLE 1. Properties and characteristics of the EHPS.

\section{MAterials AND Methods}

\subsection{EXTREMELY HIGH PLASTICITY SOIL (EHPS)}

The soil selected in this study is plastic clay soil, it is a naturally occurring problematic soil with a clay content higher than $80 \%$. The disturbed soil sample used in this study was obtained from Al-Anbar province (Latitude $32^{\circ} 31^{\prime} \mathrm{N}$ and longitude $41^{\circ} 54^{\prime} \mathrm{E}$ ), Iraq. The basic properties of the soil have been determined and are shown in Table 1. According to BS 5930, the selected soil was classified as "clay of extremely high plasticity" "CE". Throughout this paper, the selected soil of extremely high plasticity has been denoted as (EHPS). The EHPS has a high plasticity index ( $I p=$ $96 \%$ ) with an activity value (A) of 1.17 . Based on Ip and $A$ values and the potential expansivity, the EHPS can be classified as "Very High", 33.

The chemical composition of EHPS, Table 1 indicates that the element of silicon is the most abundant, also, EHPS has a high content of calcium component, with the other elements being aluminium, iron, etc. The qualitative X-Ray diffraction (X.R.D.) analysis indicated that montmorillonite and Quartz are the main constituents of the soil, [34. The value of "cation exchange capacity" for EHPS is $80 \mathrm{meq} / 100 \mathrm{~g}$. As it can be seen, the results of physical, chemical, mineralogical tests indicate that the studied EHPS is potentially expansive.

\subsection{BUILDING STONE DEBRis (BSD)}

In Iraq, natural stones are an essential building material used in construction. They are used for the 


\begin{tabular}{|c|c|c|}
\hline Material Property & DBSC & DBSF \\
\hline Color & very pole brown & light yellowish brown \\
\hline Specific Gravity, Gs & 2.78 & 2.71 \\
\hline Liquid limit, $w_{L}(\%)$ & 28 & 32 \\
\hline Plastic limit, $w_{P}(\%)$ & - & - \\
\hline Plasticity Index, Ip (\%) & NP & NP \\
\hline $\mathrm{D} 10(\mathrm{~mm})$ & 0.13 & 0.001 \\
\hline D30 (mm) & 0.18 & 0.0028 \\
\hline D50 (mm) & 0.23 & 0.0065 \\
\hline D60 (mm) & 0.26 & 0.01 \\
\hline $\mathrm{Cu}$ & 2 & 10 \\
\hline $\mathrm{Cc}$ & 0.99 & 0.78 \\
\hline British Soil Classification System, BSCS & SP & $\mathrm{M}$ \\
\hline USCS & $\mathrm{SP}$ & ML \\
\hline $\mathrm{CaO}$ & & 63.41 \\
\hline $\mathrm{Fe} 2 \mathrm{O} 3$ & & 20.09 \\
\hline $\mathrm{SiO} 2$ & & 5.30 \\
\hline $\mathrm{K} 2 \mathrm{O}$ & & 1.19 \\
\hline $\mathrm{MnO}$ & & 0.15 \\
\hline
\end{tabular}

TABle 2. Properties and characteristics of BSD.

\begin{tabular}{lccccc}
\hline DBS Content, $\%$ & 10 & 20 & 30 & 40 & 50 \\
\hline \multirow{2}{*}{ Designation } & DBSC10 & DBSC20 & DBSC30 & DBSC40 & DBSC50 \\
& DBSF10 & DBSF20 & DBSF30 & DBSF40 & DBSF50 \\
\hline
\end{tabular}

TABLE 3. Designation of the produced EHPS-BSD mixtures.

masonry of buildings. Also, natural stones are preferred for finishing and facing works. Mostly, natural massive rocks are the main source of the building stones in Iraq. The building stone debris (BSD) was selected as a solid additive to ameliorate the geotechnical characteristics of extremely high plasticity soil (EHPS).

The BSD used was obtained and collected from a dumping area at one of the construction sites in Baghdad city, the capital of Iraq. BSD was prepared in the laboratory in steps including cleaning, drying, crushing, and sieving. After cleaning the surface of the BSD from foreign materials, drying at a temperature of $105^{\circ} \mathrm{C}$ took place, the BSD was crushed in two stages. A small hammer was first used to crush the BSD manually, while in the second stage, BSD was crushed mechanically. Subsequently, the crushed BSD was divided into two sets. The crushed BSD in the first set was sieved on sieve No. 40, the remaining material was then subjected to further mechanical crushing, then sieved again to ensure all material passed through the sieve 40 . The crushed BSD from the second set was subjected to further crushing using the Los Angeles machine. The resultant material was sieved on sieve No. 200, and the residual material was then returned to the Los Angeles machine for further crushing. Such a process was continued until all the material passed the sieve No. 200.
To study the effect of the gradation of BSD on the geotechnical properties of the soil, two different gradations were prepared, the first one is the coarse gradation that included the materials passing through the sieve No. 40, denoted BSDC, while the second gradation is the gradation of fine material, obtained from materials passing the sieve No. 200, denoted BSDF.

The basic properties of the BSD are shown in Table 2 Clearly, the BSD is a non-plastic material and has higher Gs values than EHPS. BSD's chemical components show that, notably, the $\mathrm{Ca}$, Fae, and $\mathrm{Si}$ are the main elements of BSD. Accordingly, it can be confirmed that the selected stabilising agent in this work shows a low-carbon content, in other words, it is an eco-friendly agent.

\subsection{Preparation of SPecimens and LABORATORY TESTING PROGRAMME}

The EHPS was mixed with different dosages of BSDC and BSDF (Table 3). For this purpose, the dosages of $10 \%, 20 \%, 30 \%, 40 \%$, and $50 \%$ by weight of the dry soil were added to the EHPS. The EHPSBSD mixtures were prepared by mixing the dosages of BSD with EHPS to form completely homogeneous mixtures. In general, the dry mixing method was used to prepare testing soil specimens. The designation of each produced sample is shown in Table 3

The laboratory tests included Atterberg limits, linear shrinkage [35], compaction test, unconfined com- 


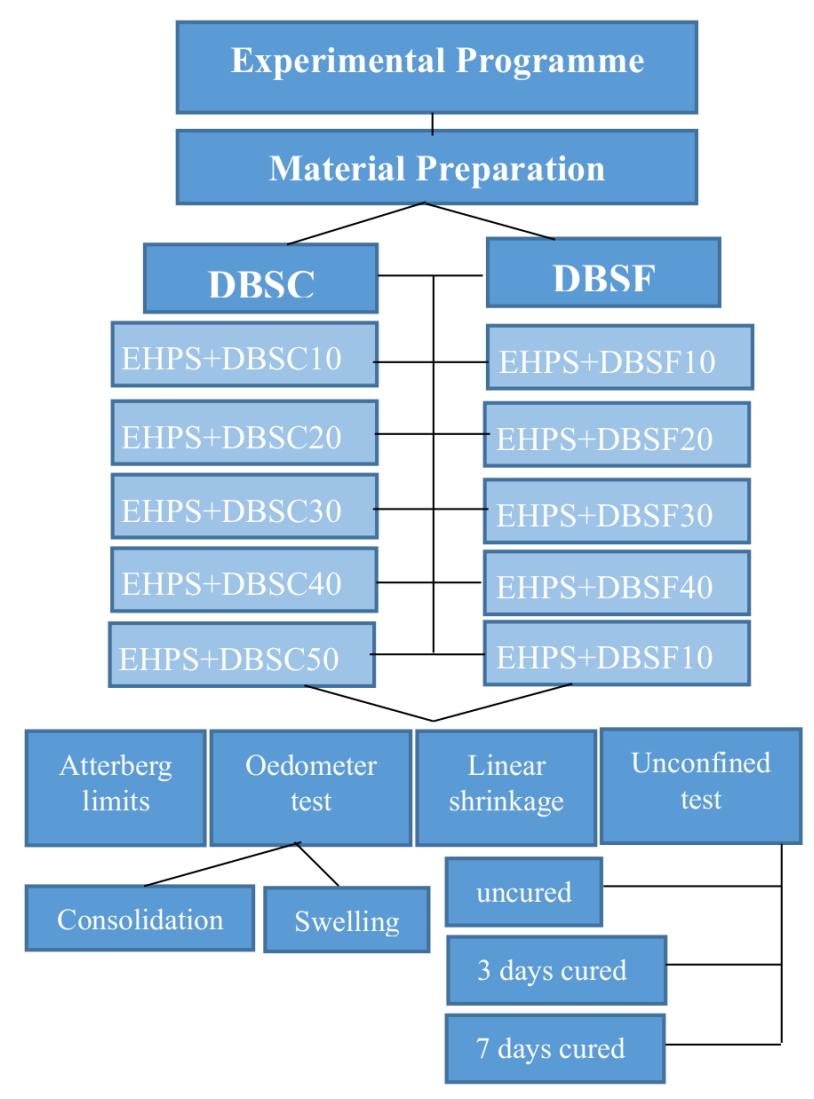

FiguRE 1. Testing programme.

pression [36], consolidation, and swelling tests [36]. The effect of curing on the unconfined compression test samples has also been included in the testing programme (see Figure 1).

Specimens were cured for 3 and 7 days. For basic tests, disturbed mixtures were used, while for engineering tests, compaction was applied to achieve the specified dry unit weights and corresponding water contents.

The compacted specimens were extruded from a standard compaction mould. The homogenous wet mixtures were prepared at an optimum water content, then compacted to a corresponding maximum unit weight inside a standard compaction mould. The specimens for engineering tests were obtained by pushing the $3.6 \mathrm{~cm}$ diameter and $7.2 \mathrm{~cm}$ height steel mould of unconfined tests inside the compaction mould. The obtained specimens were either directly tested for unconfined-compressive-strength [36] or cured for three and seven days and then tested. It should be noted that all cured specimens were weighted with a precision of $0.01 \mathrm{~g}$ after the preparation and after the completion of the curing period to ensure minimum variations and maximal consistency. The difference in weight was very little (in the second decimal of the weight), and this indicates a great accuracy of the curing process.

The compressibility of EHPS-BSD mixtures was studied by carrying out a set of oedometer tests (onedimensional-consolidation test [36]; each wet homoge- nous EHPS-BSD mixture was statically compacted inside the oedometer ring $(5 \mathrm{~cm}$ diameter and $2 \mathrm{~cm}$ height) to obtain the required unit weight. A set of swell-tests was carried out in accordance with 36 to study the volume changes of EHPS-BSD mixtures. The preparation of swell test specimens was similar to that of the consolidation test specimens. However, the height of the specimen for the swell test $(1.65 \mathrm{~cm})$ is smaller than the height of the ring $(2 \mathrm{~cm})$. This is, as stated by HEAD [37], to ensure a total lateral confining throughout the test. The swelling was measured using a dial gauge of $0.002 \mathrm{~mm} /$ division. After soaking, the following intervals were fixed to record the swelling: (0.5 min, $1 \mathrm{~min}, 2 \mathrm{~min}, 4 \mathrm{~min}, 8 \mathrm{~min}, 16 \mathrm{~min}, 30 \mathrm{~min}$, $60 \mathrm{~min}, 120 \mathrm{~min}, 180 \mathrm{~min}, 240 \mathrm{~min}, 1440 \mathrm{~min}, 2880 \mathrm{~min}$, $4320 \mathrm{~min}, 5760 \mathrm{~min}, 7200 \mathrm{~min}$, and $8640 \mathrm{~min}$ ).

\section{RESUlts AND DisCUSSION}

\subsection{Plasticity of EHPS-BSD miXtures}

The results of Atterberg's limits (liquid limit $\left(w_{L}\right)$, plastic limit $\left(w_{P}\right)$, and plasticity index (Ip) for EHPS mixed with two graded types of BSD are provided in Figure 2. There is a clear improvement of the properties of the EHPS when mixed with BSDC and BSDF. There is a characteristic reduction in $w_{L}$ due to the addition of the BSDC and BSDF. However, a higher reduction in $w_{L}$ values can be noted in EHPS-BSDC mixtures as compared to EHPS-BSDF mixtures. The percentual decrease in $w_{L}$ of EHPS was about $50 \%$ 

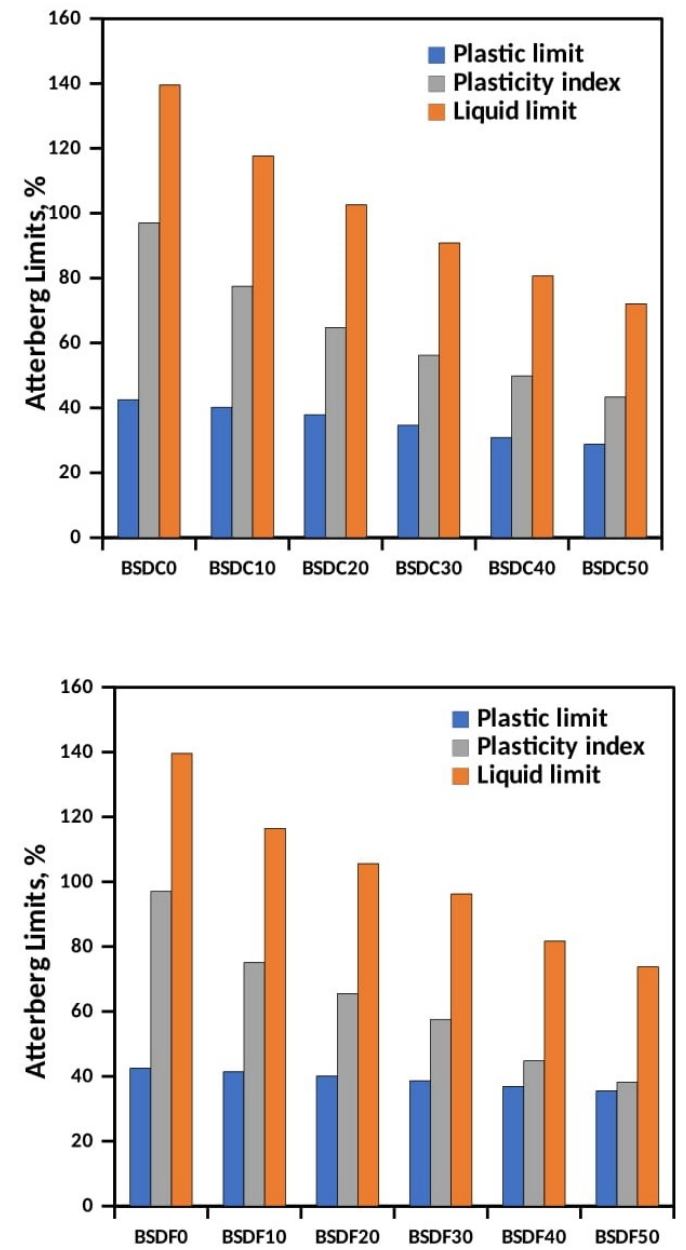

FiguRE 2. Variation of Atterberg limits with various BSD percentages.

and $49 \%$ for BSDC50 and BSDF50, respectively. This is also the case for $w_{P}$ values, $w_{P}$ decreased with increasing the content of both types of BSD. But a distinct response can be seen to the addition of BSDC in comparison with BSDF. As shown in Figure 2, $w_{P}$ decreased considerably with the addition of BSDC. The gross effect on the improvement of plasticity with BSD is a decrease in the Ip of EHPS-BSD mixtures. As for the $w_{L}$, Figure 2 clearly shows that the improvement effect of BSDF was better than that of an equal amount of BSDC. While the Ip of EHPS decreased below $35 \%$ for BSDF50, the EHPS mixed with the identical quantity of BSDC had $I p$ value of $40 \%$. In general, an increased BSD percentage led to a decrease in the $I p$. The same finding is, also, reported by [38] for expansive soil treated with "pyroclastic rock dust". As such, an immediate alteration in EHPS workability can be caused by the exchanging of calcium ions, released by the $\mathrm{CaO}$ from the BSD structure, with other ions on the structure of the EHPS. Such a cation exchange caused the $w_{L}$ to decrease and as a result, reduce $I p$. Such a reduction in $I p$ produced a more tenuous texture of EHPS-BSD
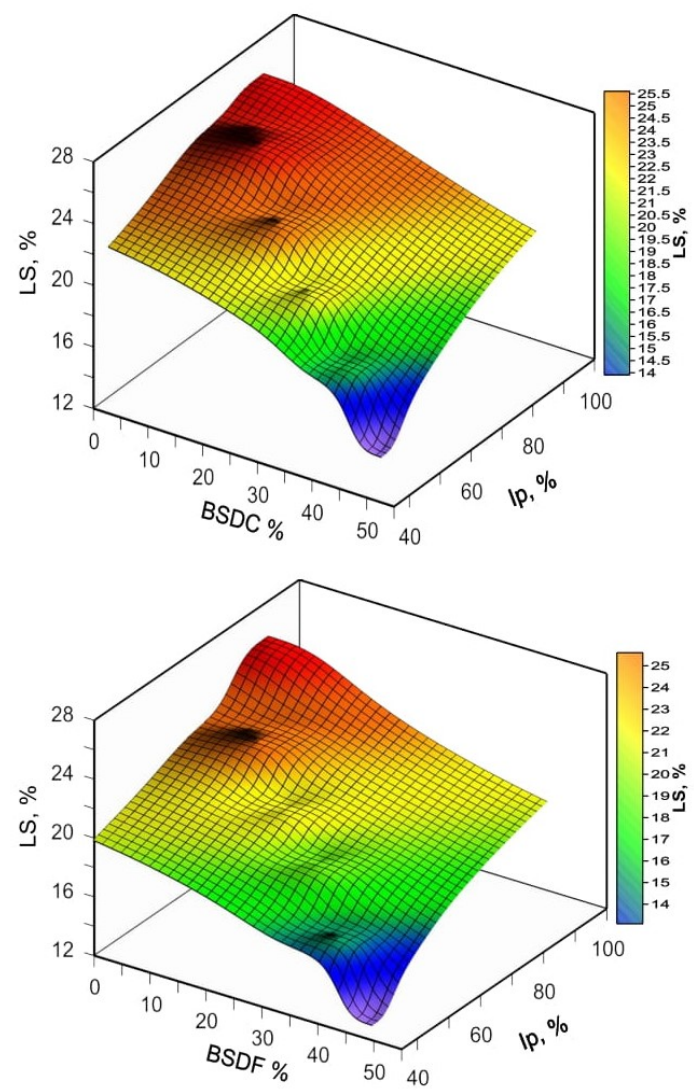

FiguRE 3. Variation of $L S$ with various BSD percentages.

mixtures and this makes the EHPS in-situ handling easier.

\subsection{LineAR SHRINKAGE $(L S)$ RESUlT}

According to the procedure presented by BS 1377 [36], Linear Shrinkage $(L S)$ values for EHPS-BSD mixtures were determined. Test specimens were prepared at a high water content (near the $w_{L}$ ) and placed in the designed mould under lab conditions. The changes that take place in the air and water phases of specimens have been analysed, and shrinkage paths have been examined for $L S$. Figure 2 shows the variation of $L S$ and $I p$ with different contents of BSD. As can be seen, when the content of BSD increased from $0 \%$ to $50 \%$, the $L S$ reduced, decreasing the $I p$. Particularly, the $L S$ of BSDC50 and BSDF50 mixtures decreased by $45.7 \%$ and $48.8 \%$, respectively, in comparison to unaltered EHPS specimens. A re-examination of Figure 3 showed that the efficiency of BSDF was higher than that of BSDC in decreasing the shrinkage values of EHPS, however, the trend of decreasing $L S$ is comparable for both the BSDC and BSDF.

The study of $L S$ included the time to reach the final drying stage (the zero-water content). The effect of the type and content of BSD on the time needed to reach the final shrinkage stage has been investigated. For each EHPS and EHPS-BSD mixtures, the water content during the drying stage was calculated at 

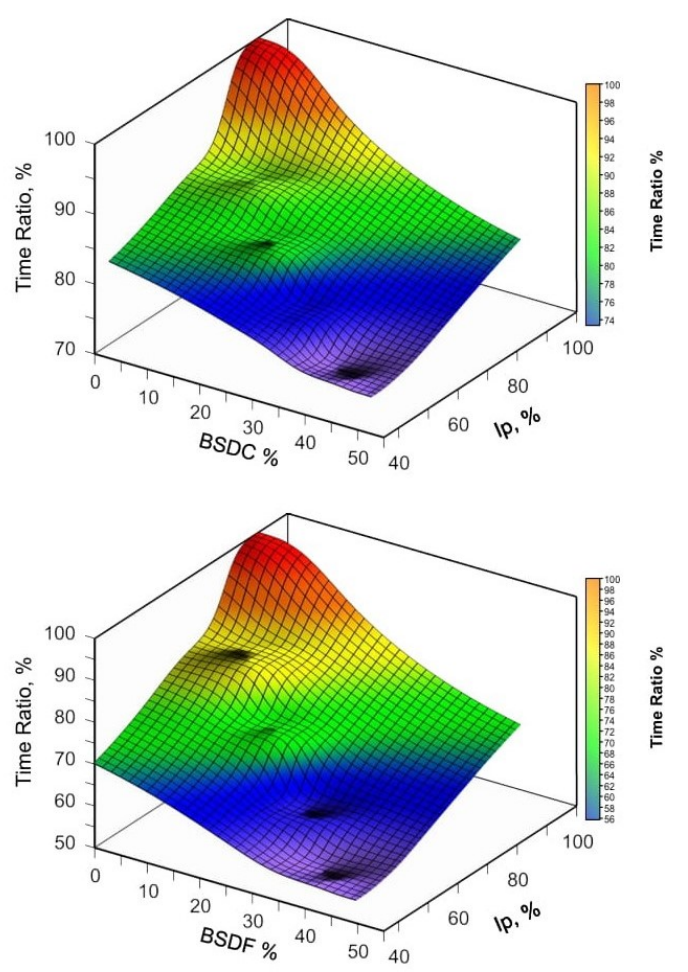

Figure 4. Effect of BSD and Ip on the time ratio of EHPS.

specified time periods, then, the ratio of final drying time for each mixture $\left(t_{n}\right)$ to that of unaltered soil $\left(t_{f}\right)$ was calculated and named as "time ratio". The variation of the time ratio with various I $p$ and BSD contents is shown in Figure 4. As illustrated, the addition of BSD decreases the time required to reach the final shrinkage stage, this decrease depends mainly on the type and content of BSD. The EHPS-BSDF mixtures required a shorter time than the EHPSBSDC mixtures. The BSDF50 required only $50 \%$ of the time, while the BSDC50 required $70 \%$.

\subsection{SheAR STRENGTH OF EHPS-BSD MIXTURES}

According to the result of the unconfined compression test, the variation of the shear strength of EHPS $\left(S_{u}\right)$ with the type and amount of BSD has been studied. The $S_{u}$ values were calculated for the uncured EHPSBSD samples tested directly after the preparation and for samples cured for three and seven days. As illustrated in Figure 5, for uncured EHPS-BSDC samples, there is a slight change in $S_{u}$ after the addition of BSDC, which indicates the importance of the curing period on the generation of a pozzolanic reaction. This was proved by curing the EHPS-BSDC samples for three and seven days, Figure 5, in which a significant increase in $S_{u}$ values has been noted. This may be attributed to a change in the soil matrix due to the formation of cementation agents as a result of pozzolanic reaction during the curing period. In contrast, the early generation of strength was noted for both
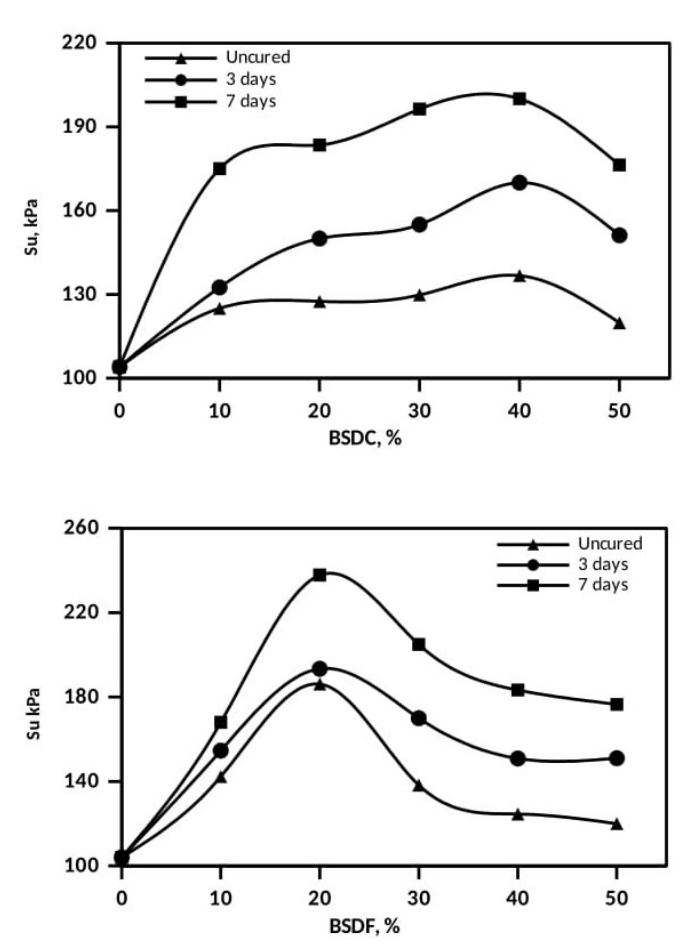

Figure 5. The effect of the type and content of BSD and curing period on $S_{u}$ of EHPS.

uncured and cured EHPS-BSDF samples. The gradation of BSD has a major role in strength development. The start of the pozzolanic reaction is mainly affected by the fineness of pozzolanic additives. In fact, the pozzolanic reaction is starting earlier for materials with a paramount fineness, as such materials have a noticeably larger surface area [39 41].

The influence of curing periods on $S_{u}$ of EHPS-BSD samples is well very noticeable in Figure 5. A significant improvement in $S_{u}$ can be noted for EHPS-BSDF samples in comparison to EHPS-BSDC samples. In fact, this improvement is not absolute, it depends on the content and the type of the BSD. It was found that the shear strength begins to develop and increase with the increase in the content of both types of BSD until it reached an optimal value. Beyond this value, the shear strength begins to decrease, but the final result of the shear strength remains higher than that of the unaltered soil. Regardless of the curing period, the optimal EHPS-BSD mixtures for this work were BSDC40 and BSDF20. Based on the observation, it can be concluded that the content of BSD, up to an optimal value, supports the pozzolanic reaction required to form the cementitious materials for the amelioration of the $S_{u}$. A further addition of BSD then showed the same result as adding sand or silt materials, such materials lead to a reduction in the shear strength of the EHPS-BSD mixtures. 

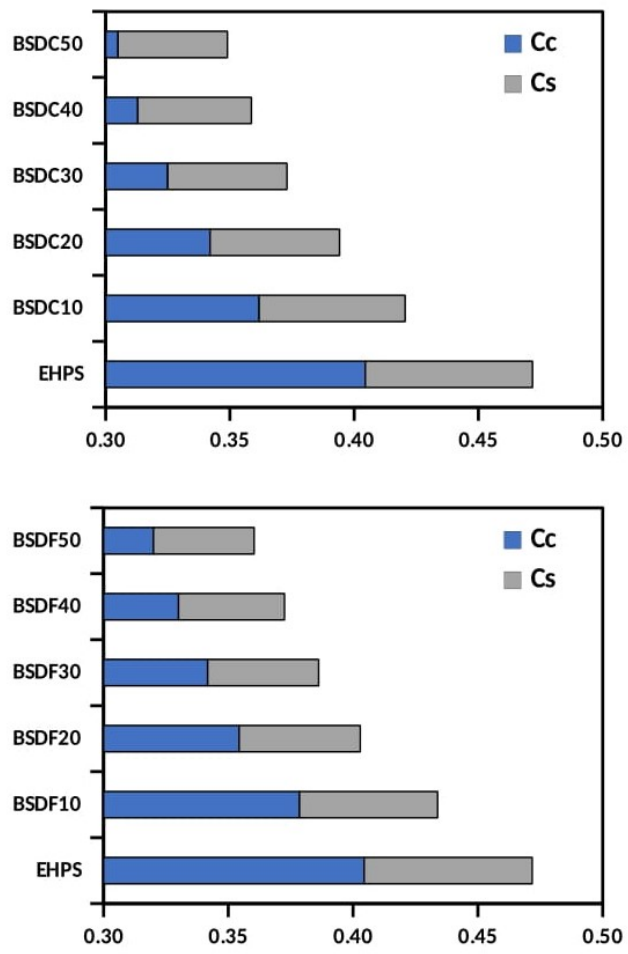

Figure 6 . The effect of the type and content of BSD on $C c$ and $C s$ of EHPS.

\subsection{Compressibility of EHPS-BSD MIXTURES}

The compressibility of EHPS-BSD mixtures has been examined in the one-dimensional-consolidation test. The compression index $(C c)$ and swelling index $(C s)$ values obtained from this test are plotted in Figure 6 There is a clear effect of BSD on the compressibility of EHPS, regardless of the gradation type of BSD, both $C c$ and $C s$ were reduced with an increasing BSD content. For BSDC50 and BSDF50, the addition of $\mathrm{BSD}$ reduces $(21$ to $25 \%$ ) the $C c$ values, while the reduction in $C s$ values ranged from (35 to $40 \%$ ). In other words, a lesser value of consolidation settlement can be expected for EHPS due to the addition of BSD.

The reaction of BSD with EHPS coincides with the reaction of "pyroclastic rock dust" with an expansive soil. The addition of pyroclastic rock alters the clay minerals due to larger sand-sized grains, and this leads to a reduction of the water absorption rate, as a result, an immediate modification in soil swell properties takes place 38 .

\subsection{Swelling of EHPS-BSD MIXTURES}

The efficiency and performance of the BSDC and BSDF in mitigating the potential of EHPS to swell have been included in this work. The results of the swell-test for the designated specimens were used to determine the swell potential $(S P)$ and the swelling pressure $(P s)$. Figure 7 highlights the variation of $S P$ with BSD content; the $L S$ values are also presented in
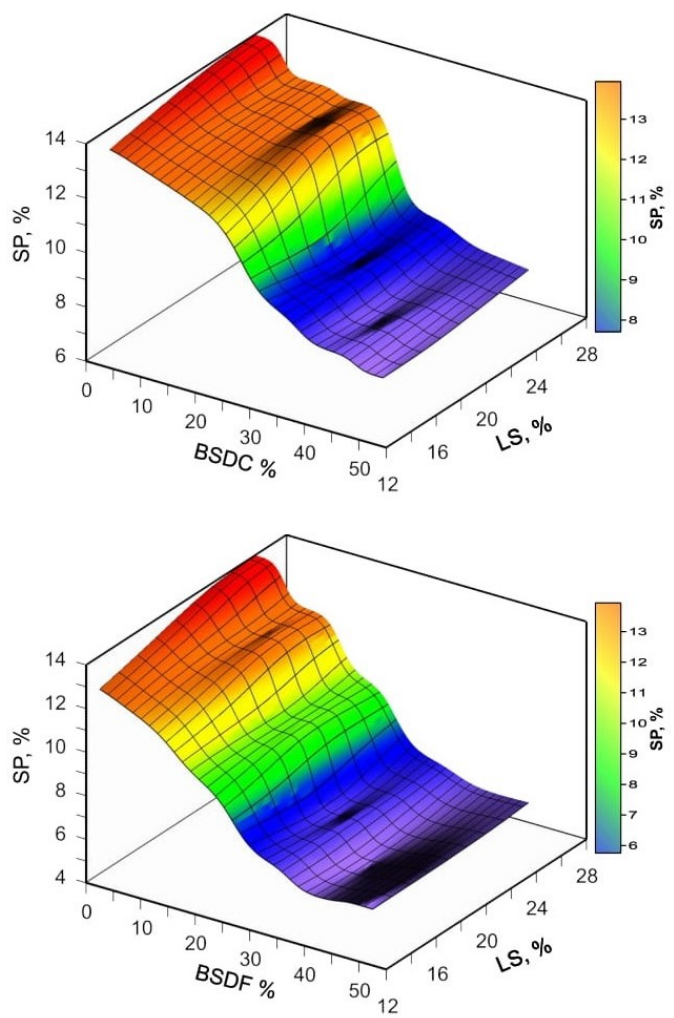

Figure 7. Variation of $S P$ and $L S$ with various BSD percentages.

this figure. It is clear that both BSD types are efficient in mitigating the $S P$ values. There is a non-linear decrease in $S P$ and $L S$ values with an increasing BSD content. However, the values of $S P$ for EHPS-BSDF specimens are significantly lesser than those for EHPSBSDC specimens. For the BSDF50 specimen, the $S P$ value was $6 \%$. For the comparable coarse-gradation BSD type specimen (i. e., BSDC50), the $S P$ value was $7.7 \%$. Researches on the stabilisation of soils using additives with a high $\mathrm{CaO}$ content showed that such additives lead to, in addition to a cation exchange, flocculation, and agglomeration of soil grains. As a result of these two phenomena, larger particles form by flocking of the small particles together [42, 43]. The clear result of using such additives is a considerable reduction in the volume changes in the soil.

Figure 8 illustrates the axial strain-log pressure curves for EHPS-BSD mixtures. The swell pressure $(P s)$ values were determined from these curves. The variation of $P s$ with the applied pressure is shown in Figure 8. It can be seen that, under various applied pressures and for both BSD types, all the EHPS-BSD specimens showed the same trend in axial strain-log pressure curves. It was noted that the time to achieve $99 \%$ of the maximum soil swell decreases with increasing the content of BSD, for BSDC50, the time was about $40 \%$ of that required to reach the maximum swell of unaltered EHPS. However, as the applied pressure increased, the reduction in $P s$ for each EHPSBSD specimen significantly decreased, beyond a par- 

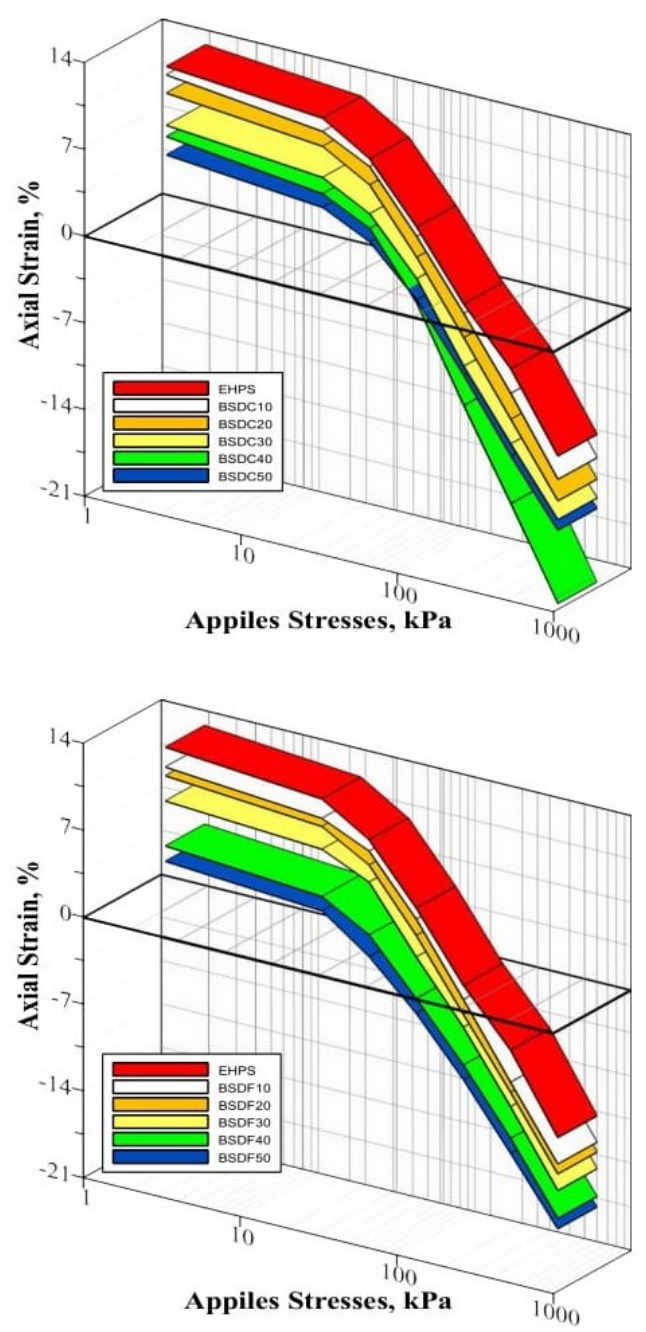

Figure 8. Axial strain-log pressure curves for EHPSBSD mixtures.

ticular pressure value, the axial strain was converted from swell (positive zone) to compression (negative zone).

As shown, the BSD mitigated the effect of the swell potential and swell pressure to various degrees. To evaluate the efficiency and performance of BSDC and BSDF in improving the EHPS, the degree of improvement or the improvement ratio $(I R)$ in $S P$ and $P s$ values have been calculated as shown below:

$$
\begin{aligned}
& I R=\frac{S P i-S P f}{S P i} \times 100 \\
& I R=\frac{P s i-P s f}{P s i} \times 100
\end{aligned}
$$

Where

$I R$ improvement ratio (\%)

$S P i$ swell potential of unaltered EHPS specimen

$S P f$ swell potential of unaltered EHPS specimen

$P s i$ swell pressure of unaltered EHPS specimen
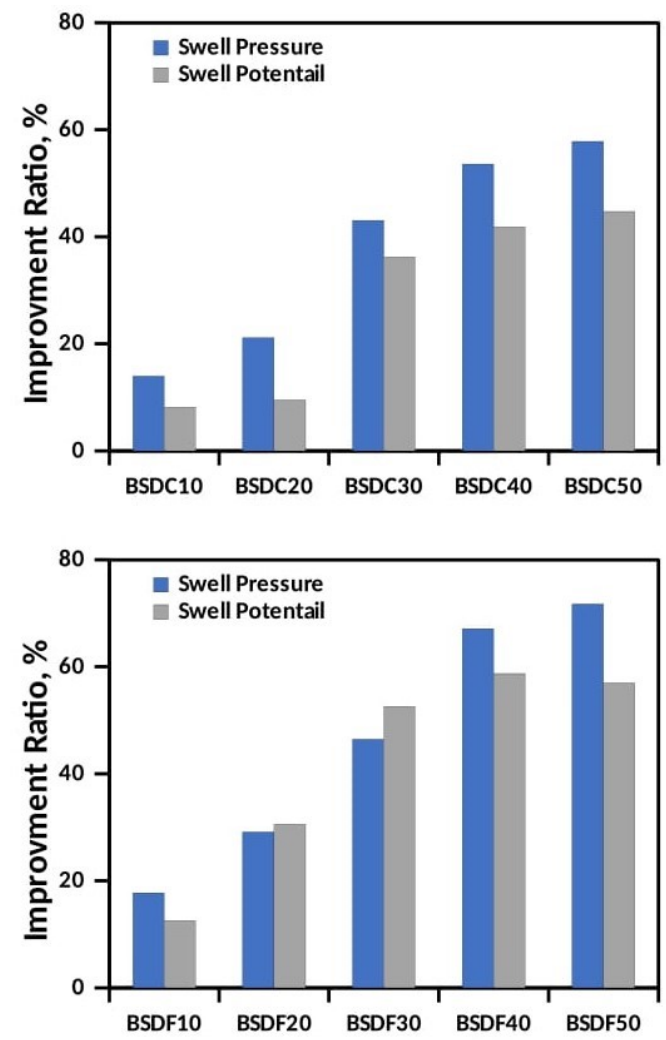

FiguRE 9. Improvement ratio for swell pressure and swell potential for EHPS-BSD mixtures.

\section{Psf swell pressure of unaltered EHPS specimen}

The variation of the improvement ratio with designated mixtures is shown in Figure 9. The statistical parameters for results shown in Figure 8 are shown in Table 4. As it can be seen, the BSD reduced the $S P$ and $P s$ to different degrees. As the BSD increased, both $S P$ and swell pressure decreased. However, the performance of the fine-sized BSD is better than that of the coarse gradation BSD. The maximum improvement ratio of $S P$ and swell pressure by using BSDF was $57.0 \%$ and $71.7 \%$, respectively. While the best performance of BSDC in improving the $S P$ and swell pressure was $44.7 \%$ and $57.8 \%$, respectively. These maximum improvement ratios were obtained for mixtures designated as BSDF50 and BSDC50. Such improvement, can be, while taking into account the aforementioned reasons, attributed to the formation of cementitious materials, as a result of the pozzolanic reaction, thus increasing the resistance of the soil to expansion [38, 44]. Overall, the addition of BSD altered the structure of expansive particles and caused a mitigation of the soil swelling potential.

\section{Conclusions}

In this experimental research, the following findings have been obtained:

(1.) There is a characteristic reduction in $w_{L}$ due to the addition of the BSDC and BSDF. The percentual decrease in $w_{L}$ of EHPS was about $50 \%$ 


\begin{tabular}{lcccc}
\hline \multirow{2}{*}{ Parameters } & \multicolumn{2}{c}{$P s$} & \multicolumn{2}{c}{$S P$} \\
\cline { 2 - 5 } & DBSC & DBSF & DBSC & DBSF \\
\hline mean & 162 & 145 & 11 & 9 \\
COV & 34 & 46 & 26 & 38 \\
standard deviation & 55 & 67 & 3 & 3 \\
\hline
\end{tabular}

TABle 4. Various statistical parameters for $S P$ and $P s$.

and $49 \%$ for BSDC50 and BSDF50, respectively. This is also noted for $w_{P}$ and $I p$ values. The $I p$ of EHPS declined below $35 \%$ when mixed with BSDF50, while the EHPS mixed with the identical quantity of BSDC resulted in Ip value of $40 \%$. BSD made the texture of EHPS more tenuous.

(2.) The improvement of EHPS with BSD reduces the amount of shrinkage. Increasing the BSD content from $0 \%$ to $50 \%$ reduced the $L S$, at a $50 \%$ BSD content, the percentual decrease in $L S$ was $45.7 \%$ (for BSDC) and $48.8 \%$ (for BSDF). BSDF50 reduced the time required by the EHPS to reach the final shrinkage by approximately $50 \%$.

(3.) The addition of BSD improved the $S_{u}$ of EHPS, the soil became stiffer and harder with the addition of BSD. However, the curing period, the type, and the content of BSD had an important role.

(4.) The consolidation parameters of EHPS were reduced due to the addition of BSD, the reduction was 21 to $25 \%$ in $C c$ and 35 to $40 \%$ in $C s$.

(5.) There is a non-linear decrease in the swelling potential of EHPS with an increasing content of BSD. For the BSDF50 and BSDC50, the $S P$ reduced to $6 \%$ and $7.7 \%$, respectively. The maximum reduction in swell pressure due to using BSDF and BSDC was $71.7 \%$ and $57.8 \%$, respectively.

Overall, the addition of BSD altered the structure of expansive particles and caused a mitigation of the soil swelling potential. However, BSDF was more effective. Finally, the building stone debris can present a sustainable low-carbon stabiliser significant in geotechnical applications.

\section{LIST OF SYMBOLS}

$C c$ compression index

Cs swelling index

Ip plasticity index [\%]

$I R$ improvement ratio [\%]

$L S$ linear shrinkage [\%]

$P s i$ swell pressure of unaltered EHPS specimen

$P s f$ swell pressure of unaltered EHPS specimen

$S P i$ swell potential of unaltered EHPS specimen

$S P f$ swell potential of unaltered EHPS specimen

$S_{u}$ shear strength $[\mathrm{kPa}]$

$w_{L}$ liquid limit [\%]

$w_{p}$ plastic limit [\%]

\section{REFERENCES}

[1] A. Al-Baidhani, A. J. AL-Taie. Recycled crushed ceramic rubble for improving highly expansive soil. Transportation Infrastructure Geotechnology 7(3):426-444, 2020. https://doi.org/10.1007/s40515-020-00120-z

[2] M. Ashfaq, A. A. B. Moghal, B. M. Basha, A. A. B. Moghal. Carbon footprint analysis on the expansive soil stabilization techniques. In International Foundations Congress and Equipment Expo, ASCE. 2020. https://doi.org/10.1061/9780784483411.021.

[3] A. J. Al-Taie. Practical aid to identify and evaluate plasticity, swelling and collapsibility of the soil encountered in Badrah, Shatra and Nassirya cities. Journal of Engineering and Sustainable Development 20(1):38-47, 2016.

[4] A. Al-Baidhani, A. J. Al-Taie. Shrinkage and strength behavior of highly plastic clay improved by brick dust. Journal of Engineering 26(5):95-105, 2020. https://doi.org/10.31026/j.eng.2020.05.07.

[5] A. J. Puppala, E. Wattanasanticharoen, L. R. Hoyos. Ranking of four chemical and mechanical stabilization methods to treat low-volume road subgrades in Texas. Transportation Research Record 1819(1):63-71, 2003. https://doi.org/10.3141/1819b-09.

[6] S. Horpibulsuk, C. Phetchuay, A. Chinkulkijniwat, A. Cholaphatsorn. Strength development in silty clay stabilized with calcium carbide residue and fly ash. Soils Found 53(4):477-486, 2013. https://doi.org/10.1016/j.sandf.2013.06.001.

[7] Y. J. Du, N. J. Jiang, S. Y. Li, et al. Field evaluation of soft highway subgrade soil stabilized with calcium carbide residue. Soils and Foundations 56(2):301-314, 2016. https://doi.org/10.1016/j.sandf.2016.02.012.

[8] A. Arulrajah, E. Yaghoubi, Y. C. Wong, S. Horpibulsuk. Recycled plastic granules and demolition wastes as construction materials: Resilient moduli and strength characteristics. Construction and Building Materials 147:639-647, 2017. https: //doi.org/10.1016/j.conbuildmat.2017.04.178

[9] A. J. Al-Taie, Y. Al-Shakarchi. Shear strength, collapsibility and compressibility characteristics of compacted baiji dune soils. Journal of Engineering Science and Technology 12(3):767-779, 2017. http://jestec.taylors.edu.my/Vol $\% 2012 \% 20$ issue $\%$ 203\%20March\%202017/12_3_14.pdf

[10] F. Maghool, A. Arulrajah, S. Horpibulsuk, Y. J. Du. Laboratory evaluation of ladle furnace slag in unbound pavement-base/subbase applications. Journal of Materials in Civil Engineering 29(2), 2017. https: //doi.org/10.1061/(ASCE)MT.1943-5533.0001724. 
[11] A. J. Puppala, A. Pedarla. Innovative ground improvement techniques for expansive soils. Innovative Infrastructure Solutions 2:24, 2017. https://doi.org/10.1007/s41062-017-0079-2

[12] S. Rios, N. Cristelo, A. Viana Da Fonseca, C. Ferreira. Stiffness behavior of soil stabilized with alkali-activated fly ash from small to large strains. International Journal of Geomechanics 17(3), 2017. https: //doi.org/10.1061/(ASCE) GM.1943-5622.0000783

[13] I. O. Jimoh, A. A. Amadi, E. B. Ogunbode. Strength characteristics of modified black clay subgrade stabilized with cement kiln dust. Innovative Infrastructure Solutions 3:55, 2018. https://doi.org/10.1007/s41062-018-0154-3

[14] V. Farhangi, M. Karakouzian. Design of bridge foundations using reinforced micropiles. In Proceedings of the International Road Federation Global R2T Conference \& Expo, Las Vegas, NV, USA. 2019.

[15] A. J. Al-Taie, B. S. Albusoda, S. Alabdullah, A. J. Dabdab. An experimental study on leaching in gypseous soil subjected to triaxial loading. Geotechnical and Geological Engineering 37(6):5199-5210, 2019. https://doi.org/10.1007/s10706-019-00974-2

[16] Y. Gao, J. He, X. Tang, J. Chu. Calcium carbonate precipitation catalyzed by soybean urease as an improvement method for fine-grained soil. Soils and Foundations 59(5):1631-1637, 2019. https://doi.org/10.1016/j.sandf.2019.03.014

[17] A. J. Al-Taie, A. Al-Obaidi, M. Alzuhairi. Utilization of depolymerized recycled polyethylene terephthalate in improving poorly graded soil. Transportation Infrastructure Geotechnology 7(2):206-223, 2020. https://doi.org/10.1007/s40515-019-00099-2

[18] P. S. K. Raja, T. Thyagaraj. Effect of compaction time delay on compaction and strength behavior of lime-treated expansive soil contacted with sulfate. Innovative Infrastructure Solutions volume 5:14, 2020. https://doi.org/10.1007/s41062-020-0268-2

[19] V. Farhangi, M. Karakouzian. Effect of Fiber reinforced polymer tubes filled with recycled materials and concrete on structural capacity of pile foundations. Applied Sciences 10(5):1554, 2020. https://doi.org/10.3390/app10051554

[20] V. Farhangi, M. Karakouzian, M. Geertsema. Effect of micropiles on clean sand liquefaction risk based on CPT and SPT. Applied Sciences 10(9):3111, 2020. https://doi.org/10.3390/app10093111.

[21] A. Al-Kalili, A. Ali, A. Al-Taie. Effect of metakaolin and silica fume on the engineering properties of expansive soil. Journal of Physics: Conference Series 1895:012017, 2021.

https://doi.org/10.1088/1742-6596/1895/1/012017.

[22] B. V. Venkatarama Reddy. Sustainable materials for low carbon buildings. International Journal of Low-Carbon Technologies 4(3):175-181, 2009. https://doi.org/10.1093/ijlct/ctp025

[23] N. Latifi, F. Vahedifard, E. Ghazanfari, et al. Sustainable improvement of clays using low-carbon nontraditional additive. International Journal of Geomechanics 18(3), 2018. https:

//doi.org/10.1061/(ASCE) GM.1943-5622.0001086
[24] M. P. Kumar. Cements and concrete mixtures for sustainability. In Proceedings of Structural Engineering World Congress, Bangalore, India, 2-7 November $200 \%$.

[25] L. F. Cabeza, C. Barreneche, L. Miró, et al. Low carbon and low embodied energy materials in buildings: A review. Renewable and Sustainable Energy Reviews 23:536 -542, 2013. https://doi.org/10.1016/j.rser.2013.03.017

[26] M. M. Roshani, S. H. Kargar, V. Farhangi, M. Karakouzian. Predicting the effect of fly ash on concrete's mechanical properties by ANN. Sustainability 13(3):1469, 2021

https://doi.org/10.3390/su13031469

[27] B. V. Venkatarama Reddy, A. Gupta. Tensile bond strength of soil-cement block masonry couplets using cement-soil mortars. Journal of Materials in Civil Engineering 18(1):36-45, 2006. https://doi.org/10. 1061/(ASCE) 0899-1561(2006) 18:1(36)

[28] B. V. Venkatarama Reddy, P. Kumar. Embodied energy in cement stabilized rammed earth walls. Energy and Buildings 42(3):380-385, 2010. https://doi.org/10.1016/j.enbuild.2009.10.005

[29] S. Jiao, M. Cao, Y. Li. Impact research of solid waste on the strength of low carbon building materials. In 2011 International Conference on Electrical and Control Engineering. 2011. https://doi.org/10.1109/ICECENG.2011.6058160.

[30] M. Al-Bared, I. Harahap, A. Marto. Sustainable strength improvement of soft clay stabilized with two sizes of recycled additive. International Journal of GEOMATE 15(51):39-46, 2018. https://doi.org/10.21660/2018.51.06065

[31] J. Kinuthia, J. Oti. Designed non-fired clay mixes for sustainable and low carbon use. Applied Clay Science 59-60:131-139, 2012. https://doi.org/10.1016/j.clay.2012.02.021

[32] C. Ikeagwuani, D. Nwonu. Emerging trends in expansive soil stabilisation: a review. Journal of Rock Mechanics and Geotechnical Engineering 11(2):423-440, 2019. https://doi.org/10.1016/j.jrmge.2018.08.013

[33] D. H. Van Der Merwe. Contribution to speciality session B, Current theory and practice for building on expansive clays. In Proceeding of 6th Regional Conference for Africa on SMFE, Durban, p. 166-167. 1975.

[34] N. Al-Rubaiey, F. Kadhim, A. Ati. Nano ferrites as corrosion inhibitors for carbon steel in local Iraqi bentonite mud. Engineering and Technology Journal 35(8):849-855, 2017.

[35] British Standard Institution. 1990 method of testing soils for civil engineering purposes, B.S. 1377.

[36] ASTM. 2003 annual book of astm standards, vol. 04.08. ASTM International, West Conshohocken, PA.

[37] K. Head. Manual of Soil Laboratory Testing. Whittles Publishing, Dunbeath Mill, CRC Press, Scotland, UK, 2011. 
[38] E. Ene, C. Okagbue. Some basic geotechnical properties of expansive soil modified using pyroclastic dust. Engineering Geology 107(1-2):61-65, 2009. https://doi.org/10.1016/j.enggeo.2009.03.007.

[39] J. Paya, M. Borrachero, J. Monzo, et al. Enhanced conductivity measurements techniques for evaluation of fly ash pozzolanic activity. Cement and Concrete research 31(1):41-49, 2001. https://doi.org/10.1016/S0008-8846(00)00434-8

[40] J. Tangpagasit, R. Cheerarot, C. Jaturapitakkul, K. Kiattikomol. Packing effect and pozzolanic reaction of fly ash in mortar. Cement and Concrete Research 35(6):1145-1151, 2005.

https://doi.org/10.1016/j.cemconres.2004.09.030.

[41] M. R. Jones, A. Mccarthy, A. Booth. Characteristics of the ultrafine component of fly ash. Fuel 85(16):2250-2259, 2006.

https://doi.org/10.1016/j.fuel.2006.01.028
[42] A. Jha, P. Sivapullaiah. Mechanism of improvement in the strength and volume change behavior of lime stabilized soil. Engineering Geology 198:53-64, 2015. https://doi.org/10.1016/j.enggeo.2015.08.020.

[43] A. Amadi, A. Okeiyi. Use of quick and hydrated lime in stabilization of lateritic soil: comparative analysis of laboratory data. International Journal of Geo-Engineering 8:3, 2017. https://doi.org/10.1186/s40703-017-0041-3.

[44] L. Krishnaraj, D. Joshua Giftson, L. Tamilvannan, P. T. Ravichandran. Study on effect of fineness and pozzolanic reaction of fly ash on mechanical properties of cement mortar. International Journal of Applied Engineering Research 10(9):14292-14297, 2015. https://www.researchgate.net/publication/ 303522067_Study_on_Effect_of_Fineness_and_ Pozzolanic_Reaction_of_Fly_Ash_on_Mechanical_ Properties_of_Cement_Mortar 